\title{
The times they are a changin'
}

$\mathrm{I}$ $\mathrm{t}$ is with great excitement that I write on behalf of the critical care community to celebrate the partnership between the Canadian Critical Care Society (CCCS) and the Canadian Respiratory Journal. Since assuming the role of Editor-in-Chief in 2011, Dr Peter Paré has championed the strategic direction that was charted by the executive of the Canadian Thoracic Society (CTS) and the previous Editor-inChief, Dr Nick Anthonisen. Their goal was to enhance the breadth and scope of the Journal to reflect the activities of the CTS and to embrace the work of other researchers and increase the impact of the Journal on practice (1).

For the CCCS, this partnership represents an opportunity to celebrate the success of research in critical care and our ability to foster the development of young investigators. Critical care research in Canada has a rich history, including pioneers such as Peter Macklem, Charlie Bryan and Bill Sibbald, and the success of the Canadian Critical Care Trials Group (CCCTG). Since its inaugural meeting held at Emerald Lake (Field, British Columbia) in September 1989, the CCCTG has flourished under the leadership of Tom Todd, Deborah Cook and John Marshall. More recently, Paul Hebert has assumed the role of chair of the CCCTG and is looking toward solidifying its strategic direction. The CCCTG has achieved world acclaim and an enviable level of productivity through a remarkably 'Canadian' collegial approach that has led to the publication of more than 120 articles, including 14 in the New England Journal of Medicine. The work of the CCCTG complements the tremendous contributions in clinical, basic science and health outcomes research in critical care across this country. It is perhaps fitting, then, that the CRJ has made a place for critical care, given the contribution that Canadian critical care researchers have made to the world.
Our new partnership with the CRJ also brings critical care to a broader community. The challenges faced in times of crisis, ranging from pandemics to environmental disasters, have raised the profile of critical care and galvanized efforts to ensure the optimal delivery of human and technological resources. We also face ethical dilemmas in the provision of end-of-life care, organ donation and struggle with balancing advanced care with the realities of the human condition. Although not unique to critical care, we are often confronted with an intense version of challenges faced by many practitioners. In this regard, we hope to be able to provide value to the general scientific community and readership through our editorial contributions and policy statements on the withdrawal of life-sustaining treatments, end of life care, palliative care and organ donation.

This new relationship also allows us an opportunity to enhance communication with our critical care community, stakeholders and partners - to share our views, best practices, guidelines, systematic reviews and latest strategies to translate science into practice. Therefore, I call upon my colleagues from across Canada and the globe to submit their scholarly work to this Journal, to rise to the challenge of the Editors of the CRJ; to enhance the profile of the Journal and serve the needs of its readership and, ultimately, our patients.

John Granton MD FRCPC, Canadian Critical Care Society,

University Health Network, Toronto, Ontario

\section{REFERENCE}

1. Fox G. Winds of change at the Canadian Respiratory Journal. Can Respir J 2011;18:127. 


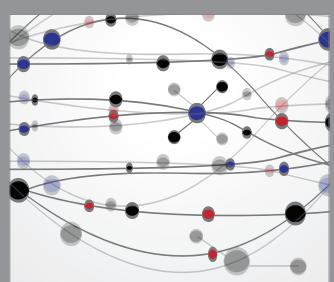

The Scientific World Journal
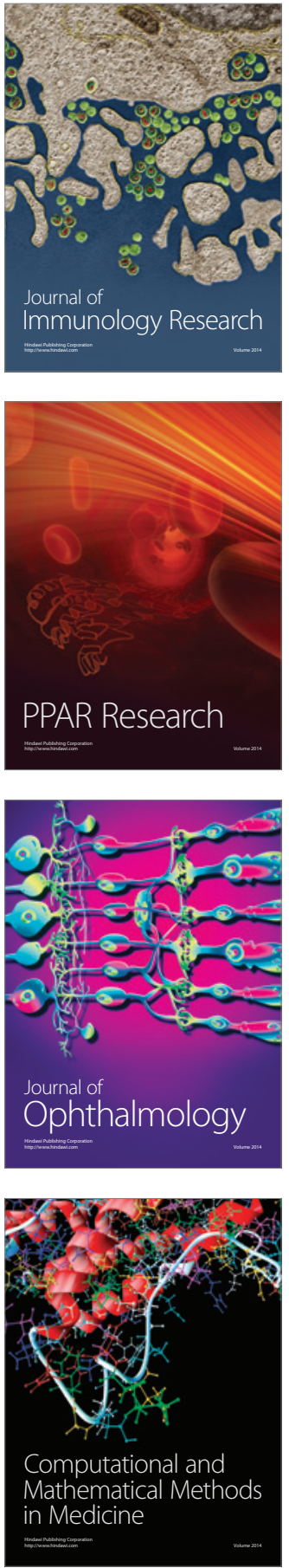

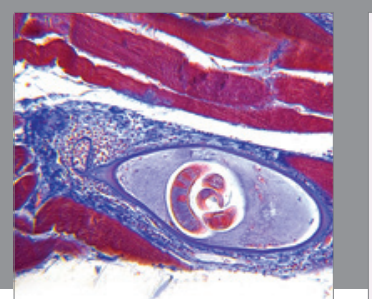

Gastroenterology Research and Practice

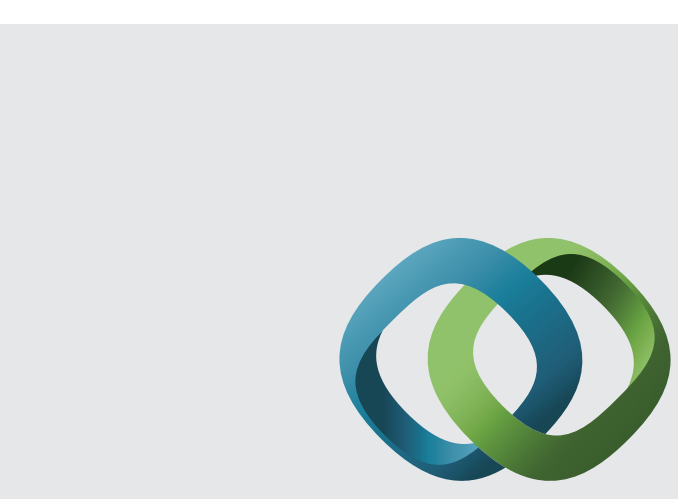

\section{Hindawi}

Submit your manuscripts at

http://www.hindawi.com
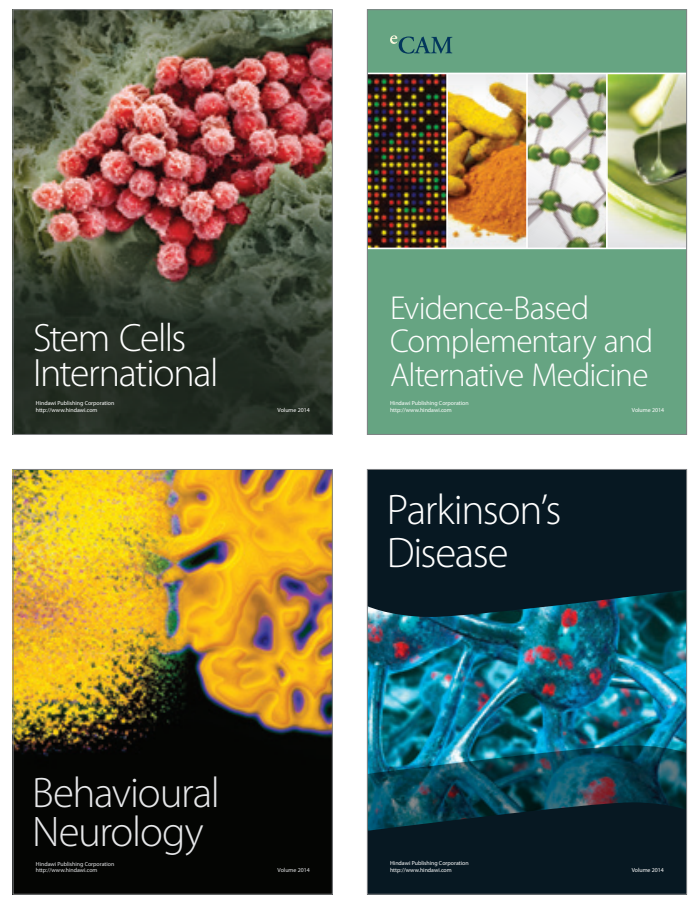
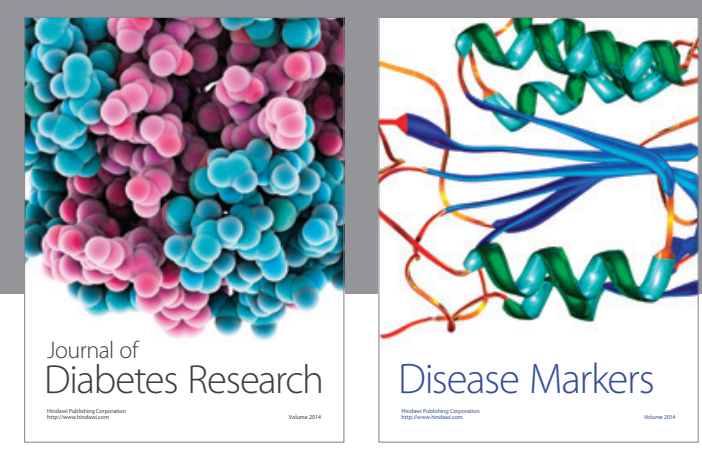

Disease Markers
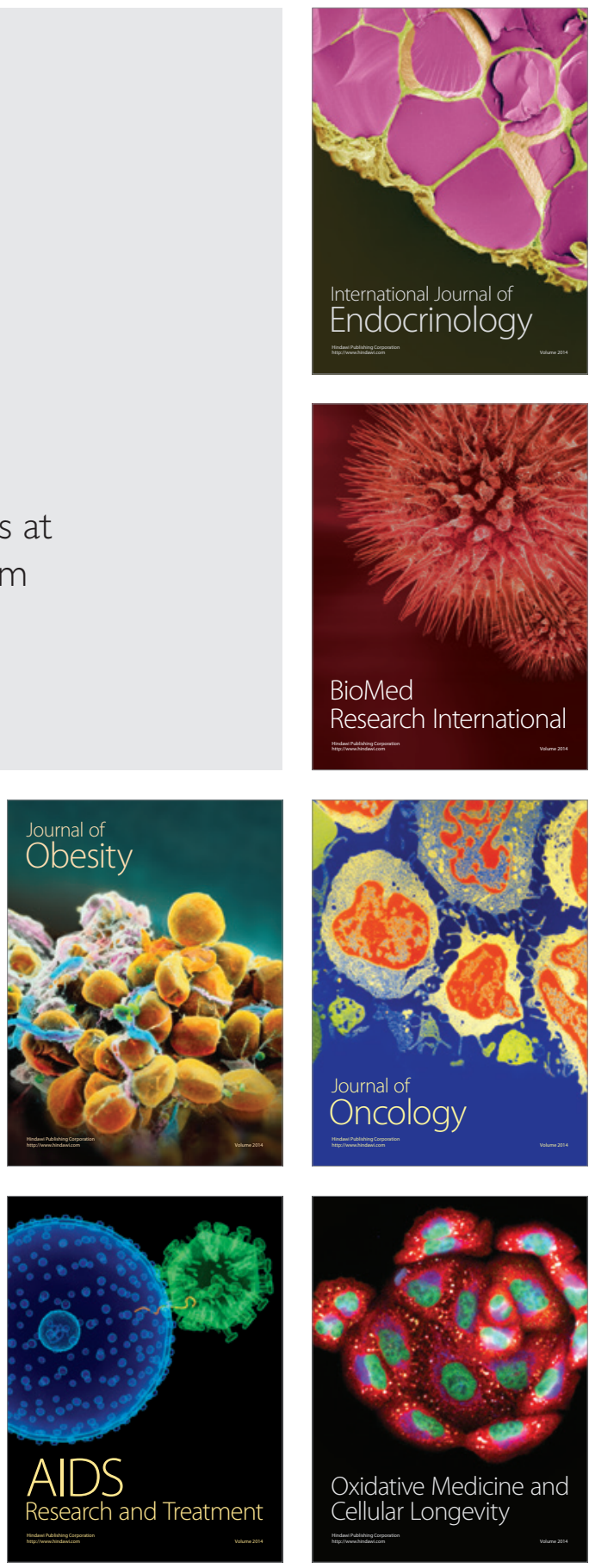